\title{
Predictors of Practitioners' Use of Recommended Early Childhood Intervention Practices
}

\author{
Carl J. Dunst ${ }^{1}$, Mary Beth Bruder ${ }^{2}$, Susan P. Maude ${ }^{3}$, Melissa Schnurr ${ }^{4}$, Angela Van Polen ${ }^{4}$, Gloria Frolek Clark ${ }^{5}$, \\ Amanda Winslow ${ }^{4} \&$ Dee Gethmann ${ }^{4}$ \\ ${ }^{1}$ Orelena Hawks Puckett Institute, Asheville, North Carolina, USA \\ ${ }^{2}$ University of Connecticut Health Center, Farmington, Connecticut, USA \\ ${ }^{3}$ Maude Consulting, Jasper, Georgia, USA \\ ${ }^{4}$ Iowa Department of Education, Des Moines, Iowa, USA \\ ${ }^{5}$ Private Practice, Adel, Iowa, USA \\ Correspondence: Carl J. Dunst, Orelena Hawks Puckett Institute, Asheville, North Carolina, USA. E-mail: \\ cdunst@puckett.org
}

Received: April 3, 2020

doi:10.5539/ies.v13n9p36
Accepted: May 8, 2020 Online Published: August 24, 2020

URL: https://doi.org/10.5539/ies.v13n9p36

\begin{abstract}
Findings from research syntheses of adult learning and in-service training studies identified the importance of professional development as a factor influencing practitioner use of recommended and evidence-based intervention practices. These relationships were used to test the hypothesis that practice-specific evidence-based capacity-building professional development would be related to early childhood practitioners' reported use of recommended early childhood intervention practices. The participants were practitioners working with birth to 3-year-old, 3- to 5-year-old, or birth to 5-year-old children with identified disabilities, developmental delays, or at-risk conditions in home-based or center-based programs or both. The predictors included three practitioner background variables (e.g., years of professional experience) and three professional development variables (e.g., evidence-based professional development practices). Results indicated that the three professional development practice variables accounted for significant amounts of variance in the practitioners' reported use of 10 different practices beyond that accounted for by the three background variables. The findings highlight the importance of evidence-based capacity-building professional development as a factor influencing practitioners' judgments of their use of recommended practices.
\end{abstract}

Keywords: early childhood intervention, recommended practices, practitioner background characteristics, professional development, regression analyses

\section{Introduction}

Darling-Hammond and McLaughlin (1995) once stated that "Policies must keep pace with new ideas about what, when, and how teachers learn and must focus on developing schools' and teachers' capacities to be responsible for student learning" (p. 597). What, when, and how teachers learn to use evidence-based or recommended practices is multiply determined (e.g., Park \& Turnbull, 2003; Rosenberg, Bart, Ratzon, \& Jarus, 2013; Turner, Nicholson, \& Sanders, 2011). Both personal (Downer, Locasale-Crouch, Hamre, \& Pianta, 2009) and contextual (Van keer \& Maes, 2016) factors have been found to influence teachers and other practitioners' use of different kinds of intervention practices. This is especially the case in birth to age three early intervention programs and 3to 5-year-old preschool programs where personal and contextual factors are much more varied. Unlike practices in K-12 schools, early intervention and preschool programs differ as a function of setting (e.g., home-based vs. center-based), primary providers (e.g., early childhood educators vs. therapists), the focus of intervention (e.g., child vs. family), and type of instruction (e.g., constructivist vs. didactic) among other factors.

Findings from several studies indicate that early childhood practitioners' use of different kinds of early childhood intervention practices, and their beliefs about their abilities to use the practices, is related to several different factors (e.g., Bruder \& Dunst, 2008; Hider, 2000; Rapport, McWilliam, \& Smith, 2004). Results from these studies indicate that practitioner use of early childhood intervention practices is related to professional discipline (Dunst \& Bruder, 2014; McWilliam \& Bailey, 1994), years of professional experience (McKenzie, 2013; 
Weintraub Moore \& Wilcox, 2006), type of early childhood intervention program and setting (Dunst, Bruder, \& Espe-Sherwindt, 2014; McWilliam \& Bailey, 1994), the characteristics of the children served by practitioners (McWilliam \& Bailey, 1994; Ruble \& McGrew, 2013), and both the availability and types of professional development (Bruder, Dunst, Wilson, \& Stayton, 2013; Martinez, 2017).

The one factor that has proven especially important in terms of explaining practitioner use of recommended practices is the type of professional development (PD) afforded educators in general and early childhood practitioners in particular. Findings from reviews and syntheses of adult learning and in-service studies have identified the particular types of $\mathrm{PD}$ practices that are associated with practitioner use of the practices that are the focus of professional development (Desimone, 2009; Dunst, Bruder, \& Hamby, 2015; Dunst, Trivette, \& Hamby, 2010; Egert, Fukkink, \& Eckhardt, 2018; Guskey \& Yoon, 2009). These include (1) Professional development specialist (PDS)-provided information about the early childhood intervention practices, (2) PDS description and demonstration of the use of the practices, (3) authentic practitioner skill development experiences for learning to use the practices, and (4) PDS coaching and performance feedback to reinforce knowledge and skill acquisition. Research also indicates that the combined use of all four types of practices is associated with optimal learner outcomes (Dunst \& Trivette, 2012). Recent findings from professional development studies indicate that an explicit emphasis on building and strengthening practitioner capacity to use early childhood intervention practices is related to optimal learner outcomes (Dunst, Espe-Sherwindt, \& Hamby, 2019; Erickson, Noonan, Brussow, \& Carter, 2017). Findings also indicate that more frequent provision of this type of professional development has value-added benefits in terms of practitioner adoption and use of the practices that are the focus of PD (Knoche, Kuhn, \& Eum, 2013). The frequent provision of PD that includes the four core elements described above is operationally defined as capacity-building PD where the effects are manifested in terms of practitioners' self-efficacy beliefs about one's ability to competently use the practices that are the focus of professional development (Bozack, 2008; Dunst, Espe-Sherwindt, \& Hamby, 2019; Sheppard, Brown, \& Dibbon, 2009; Yoo, 2016).

The early childhood intervention practices that were the focus of investigation were the 10 different sets of the Council for Exceptional Children Division for Early Childhood (DEC) recommended practices (Division for Early Childhood, 2014). These include assessment and evaluation practices, instructional practices, environmental arrangements and adaptations, family-focused practices, teaming and collaboration practices, and program transition practices. "The DEC recommended practices were developed to provide guidance to practitioners and families about the most effective ways to improve learning outcomes and promote the development of young children, birth through five years of age, who have or are at-risk for developmental delays or disabilities" (Division for Early Childhood, 2014, p. 1).

\subsection{Purpose of the Study}

A multi-step data analysis procedure was used to identify the predictors of practitioners' use of the early childhood intervention recommended practices. The variance accounted for by the background variables (professional discipline, years of practitioner experience, age of children served) were first determined followed by the variance accounted for by (1) frequency of PD and (2) types of PD (evidence-based capacity-building). The background variables are ones that are related to differences in practitioner use of recommended or evidence-based practices as described above. The PD variables are ones that research indicates are important PD practices influencing practitioner use of recommended and evidence-based practices also as described above. The three primary research questions that were the focus of analysis were:

1) Are practitioner judgments of PDS use of evidence-based capacity-building PD practices related to practitioners' reported use of recommended early childhood intervention practices?

2) Do the evidence-based capacity-building professional development measures account for significant amounts of variance in practitioners' use of recommended early childhood practices beyond that accounted for by the practitioner background variables?

3) Are the relationships between the three professional development measures the same or different for the different types of early childhood recommended practices?

The analyses were performed as part of one State's efforts to identify early childhood intervention practitioners' need for different types of PD to inform future in-service professional development activities. This paper includes the results of efforts to identify the personal and contextual factors that account for the reported use of the recommended practices that were the focus of investigation. 


\section{Method}

\subsection{Participants}

The participants were practitioners in different types of early intervention and preschool programs in one Midwestern state. Invitations to participate in the study were sent to the directors of all of the state intermediate education agencies (IEAs) responsible for birth to age three early intervention programs and the directors of all state local education agencies (LEAs) responsible for 3- to 5-year-old preschool programs. The invitations were sent by email and included a description of the purpose of the survey, an electronic version of the instrument, and a request to forward the email with the survey to early intervention and preschool program practitioners. The invitations were also sent to state professional organizations (e.g., Division for Early Childhood of the Council for Exceptional Children) who were asked to share the invitation and survey with its members. Practitioners from any discipline and any type of early childhood intervention program who provided direct services to infants and young children with and without disabilities and their families were eligible to complete the survey. Because we could not ascertain how many staff was afforded the opportunity to participate in the study, we were not able to determine a return rate. Participants were employed in all nine Area Education Agencies in the State who have responsibilities for overseeing early intervention and preschool programs in their regions. The practitioners worked with infants, toddlers, or preschool children in the children's homes, center-based programs, or other settings (e.g., community playground), or a combination of settings.

The types of early intervention and preschool programs in which the participants worked included school districts (40\%), local education agencies (37\%), Early Head Start/Head Start Programs (13\%), and other kinds of early childhood programs $(10 \%)$. The children served by school districts and local education agencies had identified disabilities or documented developmental delays as defined by IDEA Part $\mathrm{C}$ early intervention program and by IDEA 619 preschool special education program eligibility requirements. The children served in Early Head Start, Head Start, and other community programs were primarily at-risk for poor developmental outcomes due to family socioeconomic factors (e.g., poverty).

Participants had 14 different professional backgrounds. The majority of participants reported their disciplines as early childhood education or early childhood special education (70\%). Eighteen percent of the respondents were physical therapists $(4 \%)$, occupational therapists $(5 \%)$, or speech and language pathologists $(9 \%)$. Twelve percent had other professional backgrounds (e.g., social work, psychology, and nursing). Most participants (75\%) had five or more years of experience working with young children birth to 3 years of age (12\%), 3 to 5 years of age (52\%), birth to 5 years of age (13\%), or children both younger and older than 5 years of age (23\%).

\subsection{Survey}

The survey the practitioners completed asked respondents to indicate their professional discipline, years of experience in early intervention or preschool programs, the ages of the children served by the participants, and how often their program or agency provided or procured PD opportunities for the practitioners. The participants were also asked to indicate, for six different types of early childhood intervention practice areas (assessment, environment, family, instruction, teaming and collaboration, and transitions), the types of PD they received to improve their use of the practices. The types of PD included (1) information provision (readings, discussions, lectures), (2) PDS demonstrations of how to use the practices (film, video clips, live demonstrations), (3) authentic practitioner learning experiences (opportunities to improve the use of the practices), and (4) coaching/collaboration (e.g., feedback on the use of the practices). Respondents were asked to indicate which of the PD practices they received as well as could indicate none. Findings from a research synthesis of these types of practices indicate that the inclusion of all four types of practices as part of PD is associated with optimal learner benefits (Dunst \& Trivette, 2012). The practitioners were also asked to make personal judgments of whether the PD they received had capacity-building effects. These judgments were intended to be measures of the practitioners' beliefs about their abilities to use the practices to have intended outcomes and benefits (Bandura, 1997).

The survey included 47 items asking the participants to indicate the extent to which they currently used different early childhood intervention practices. The number of items per practice area ranged between 2 (transitions) and 13 (instruction). The number of respondents for each practice area ranged between 781 and 955 since the participants was asked not to complete a survey section that did not apply to their current position or role. For example, whereas all 955 participants engaged in child or family assessments, only 781 participants had responsibility for child transitions between early intervention and preschool programs or between preschool programs and kindergarten.

The responses to the items for each practice area (except transitions) were factor analyzed to construct subsets of 
practices that were the dependent measures in the regression analyses described below. Principal components factor analysis with varimax rotation (Di Franco \& Marradi, 2013) was used to identify which items for each type of practice were measuring the same constructs and therefore "went together" and could be considered indicators of the same practice for assessing the reported use of the practices. Each factor analysis produced two-factor solutions except teaming and collaboration. The types of practices in each practice area, the number of items for each type of practice, and representative items are shown in Table 1.

Table 1. Types of recommended practices that were the focus of investigation

\begin{tabular}{lcl}
\hline Recommended practices & $\begin{array}{c}\text { No. of } \\
\text { Items }\end{array}$ & \multicolumn{1}{c}{ Practice example $^{\mathrm{a}}$} \\
\hline $\begin{array}{l}\text { Assessment practices } \\
\quad \text { Traditional assessment practices }\end{array}$ & 5 & $\begin{array}{l}\text { Use assessment tools to detect child progress } \\
\text { Obtain information about child skills in daily activities }\end{array}$ \\
$\begin{array}{l}\text { Authentic assessment practices } \\
\text { Instructional practices }\end{array}$ & 6 & \\
$\quad \begin{array}{l}\text { Teaching methods } \\
\text { Instructional adaptations }\end{array}$ & 10 & Embed instruction within/across routines and activities \\
$\begin{array}{l}\text { Environment practices } \\
\text { Assistive technology }\end{array}$ & 3 & Adapt instructional strategies for dual language learners \\
$\quad \begin{array}{l}\text { Environmental arrangements } \\
\text { Family practices }\end{array}$ & 2 & Use assistive technology to promote child participation in learning experiences \\
$\quad \begin{array}{l}\text { Relationship-building practices } \\
\text { Capacity-building practices }\end{array}$ & 4 & Modify/adapt environments to promote child participation and learning \\
Teaming and collaboration & 6 & $\begin{array}{l}\text { Build trusting and respectful partnerships with families } \\
\text { practices }\end{array}$ \\
Transition practices & 5 & Work together as a team to plan and implement supports to meet child and family \\
\end{tabular}

${ }^{a}$ Abbreviated descriptions of the survey items.

\subsection{Data Preparation}

Contrast coding (Cohen, Cohen, West, \& Aiken, 2003; Davis, 2010) was used to code discipline as education $=1$ and other disciplines $=0$. This coding scheme was used since the percentage of participants who had other than educational backgrounds were less than $5 \%$ for all but one of the other disciplines where subgroup analyses were not warranted. Years of experience were coded from 1 to 16 years. Effects coding (Alkharusi, 2012) was used to code the ages of children served with the birth to 3-year-old children as the reference group. The comparison groups were practitioners working with 3- to 5-year-old children, birth to 5-year-old children, and children younger and older than 5 years of age. The frequency of PD opportunities was coded on a 4-point scale ranging from never $=0$ to quite often $=3$.

The participants were also asked to indicate for each practice area (assessment, family, etc.) whether the PD they received had capacity-building effects where capacity-building was assessed in terms of each respondent's belief about his or her ability to competently use the practices that were the focus of PD. The capacity-building question was rated on a 4-point scale ranging from not-at-all $=0$ to quite a lot $=3$. The participants were also asked to indicate for each type of practice if a PDS (1) described the practice to the practitioner, (2) demonstrated the use of the practice, (3) engaged the practitioner in the use of the practices, and (4) coached the practitioner while using the practice. Respondents could also indicate that they received none of the four types of PD practices. Contrast coding (Cohen et al., 2003; Davis, 2010) was used to code all combinations of PD practices from none $=-3$ (none of the four practices) to all four $=3$ (all four of the practices). Contrast coding is a particular type of data coding scheme that places independent variables on a continuum of investigative interest (Cohen et al., 2003); in our case, the provision of none of the PD practices to the provision of all four types of PD practices.

\subsection{Method of Analysis}

Hierarchical multiple regression analysis by sets (Cohen et al., 2003) was used to identify the predictors of practitioner use of the recommended early childhood intervention practices. This type of linear regression model is an extension of simple linear regression analysis where the order of entry and the number of the predictor variables is controlled by the investigators. As stated by Cohen et al. (2003), "The choice of a particular 
cumulative sequence of [independent variables] is made in advance (in contrast to stepwise regression) dictated by the purpose and logic of the research" (p. 158). Regression analysis by sets is recommended when different measures of the same construct, taken together, are hypothesized to be related to outcomes of interest as was the case for the four PD measures. According to Cohen et al. (2003), independent variables that are conceptually related are "grouped into sets for reasons of their substantive content and the function they play in the logic of the research" (p. 163).

The model that was tested first determined the variance accounted for by the participant background characteristics followed by the variance accounted for by the PD measures. Variance accounted for is a measure of how much variability in a dependent or outcome variable is related the how much variability there is in an independent or predictor variable. The order of entry into the analyses was professional discipline, years of professional experience, ages of children served, frequency of PD opportunities, and both types of evidence-based PD and the capacity-building effects of the PD as a set. At each step in the analyses, both the cumulative and incremental amounts of variance accounted for in the practitioner reported use of the recommended practices by the predictor variables were used as the sizes of effects for the predictor-outcome relationships. Our main interest was whether the PD measures accounted for significant amounts of variance in the dependent measures beyond that associated with the background variables (discipline, years of experience, child age). Our secondary interest was whether the PD measures were differently related to the practitioners' reported use of the practices.

\section{Results}

Ten regression analyses were conducted, one for each of the dependent measures in Table 1. Table 2 shows the results of the 10 sets of regression analyses. The analyses show which predictor measures were related to the practitioners' use of each of the 10 different early childhood intervention practices. Three sets of results are reported; those for the relationships for the cumulative effects on the practice measures, those for the unique effects of each of the predictors on the practice measures, and those for the combined effects of the professional development variables.

\subsection{Cumulative Findings}

The predictors, taken together, accounted for significant amounts of variance in the practitioners' reported use of all 10 practices as evidenced by the cumulative amount of variance accounted for in the outcome measures by the predictor measures. The variance accounted for by the five sets of predictors ranged between $10 \%$ (Assistive Technology) and 32\% (Teaming and Collaboration). The average amount of variance accounted for by the predictors of the practitioners' reported use of the practices was $18 \%(\mathrm{SD}=7)$. The results confirmed our expectation that different personal and contextual factors would be related to practitioners' reported use of the recommended practices. The findings are consistent with results in other studies where practitioners with different professional backgrounds and other predictor variables were found to be related to the use of early childhood intervention practices (e.g., McMullen, 1997; Schachter, Spear, Piasta, Justice, \& Logan, 2016). The findings add to the knowledge base by showing that the predictor variables are related to the reported use of a broad range of early childhood intervention practices and that the PD measures, in particular, were related to all 10 DEC recommended practices (Research Question 1).

Table 2. Regression results predicting practitioner use of 10 different recommended early childhood intervention practices

\begin{tabular}{lccccccc}
\hline & \multicolumn{3}{c}{ Cumulative variance } & \multicolumn{3}{c}{ Incremental variance } \\
\hline Practices/predictors & $\mathrm{R}^{2}$ & $d f$ & $p$-value & $\mathrm{I}^{2}$ & $d f$ & $p$-value \\
\hline Traditional assessment practices & & & & & & \\
$\quad$ Professional discipline & .004 & 1.944 & .050 & .004 & 1.944 & .050 \\
$\quad$ Years of practitioner experience & .021 & 2.943 & .000 & .017 & 1.943 & .000 \\
$\quad$ Child age & .025 & 5.940 & .000 & .004 & 3.940 & .237 \\
Frequency of PD ${ }^{\mathrm{a}}$ opportunities & .062 & 6.939 & .000 & .037 & 1.939 & .000 \\
$\quad$ Capacity-building PD & .118 & 8.937 & .000 & .056 & 2.937 & .000 \\
Authentic assessment practices & & & & & & \\
$\quad$ Professional discipline & .036 & 1.948 & .000 & .036 & 1.948 & .000 \\
$\quad$ Years of practitioner experience & .058 & 2.947 & .000 & .021 & 1.947 & .000 \\
$\quad$ Child age & .080 & 5.944 & .000 & .023 & 3.944 & .000 \\
\hline
\end{tabular}




\begin{tabular}{|c|c|c|c|c|c|c|}
\hline Frequency of PD opportunities & .115 & 6.943 & .000 & .035 & 1.943 & .000 \\
\hline Capacity-building PD & .154 & 8.941 & .000 & .039 & 2.941 & .000 \\
\hline \multicolumn{7}{|l|}{ Environmental arrangements } \\
\hline Professional discipline & .022 & 1.883 & .000 & .022 & 1.883 & .000 \\
\hline Years of practitioner experience & .040 & 2.882 & .000 & .019 & 1.882 & .000 \\
\hline Child age & .057 & 5.879 & .000 & .017 & 3.879 & .001 \\
\hline Frequency of PD opportunities & .089 & 6.878 & .000 & .032 & 1.878 & .000 \\
\hline Capacity-building PD & .160 & 8.876 & .000 & .070 & 2.876 & .000 \\
\hline \multicolumn{7}{|l|}{ Assistive technology } \\
\hline Professional discipline & .003 & 1.821 & .098 & .003 & 1.821 & .098 \\
\hline Years of practitioner experience & .022 & 2.820 & .000 & .019 & 1.820 & .000 \\
\hline Child age & .030 & 5.817 & .000 & .008 & 3.817 & .090 \\
\hline Frequency of PD opportunities & .054 & 6.816 & .000 & .024 & 1.816 & .000 \\
\hline Capacity-building PD & .099 & 8.814 & .000 & .046 & 2.814 & .000 \\
\hline \multicolumn{7}{|l|}{ Family relationship-building practices } \\
\hline Professional discipline & .001 & 1.849 & .276 & .001 & 1.849 & .276 \\
\hline Years of practitioner experience & .029 & 2.848 & .000 & .028 & 1.848 & .000 \\
\hline Child age & .043 & 5.845 & .000 & .014 & 3.845 & .007 \\
\hline Frequency of PD opportunities & .060 & 6.844 & .000 & .016 & 1.844 & .000 \\
\hline Capacity-building PD & .124 & 8.842 & .000 & .065 & 2.842 & .000 \\
\hline \multicolumn{7}{|l|}{ Family capacity-building practices } \\
\hline Professional discipline & .008 & 1.843 & .009 & .008 & 1.843 & .009 \\
\hline Years of practitioner experience & .031 & 2.842 & .000 & .023 & 1.842 & .000 \\
\hline Child age & .066 & 5.839 & .000 & .035 & 3.839 & .000 \\
\hline Frequency of PD opportunities & .103 & 6.838 & .000 & .037 & 1.838 & .000 \\
\hline Capacity-building PD & .249 & 8.836 & .000 & .146 & 2.836 & .000 \\
\hline \multicolumn{7}{|l|}{ Teaching methods } \\
\hline Professional discipline & .000 & 1.788 & .792 & .000 & 1.788 & .792 \\
\hline Years of practitioner experience & .034 & 2.787 & .000 & .034 & 1.787 & .000 \\
\hline Child age & .039 & 5.784 & .000 & .005 & 3.784 & .264 \\
\hline Frequency of PD opportunities & .099 & 6.783 & .000 & .061 & 1.783 & .000 \\
\hline Capacity-building PD & .160 & 8.781 & .000 & .061 & 2.781 & .000 \\
\hline \multicolumn{7}{|l|}{ Instructional adaptations } \\
\hline Professional discipline & .027 & 1.739 & .000 & .027 & 1.739 & .000 \\
\hline Years of practitioner experience & .038 & 2.738 & .000 & .011 & 1.738 & .003 \\
\hline Child age & .066 & 5.735 & .000 & .027 & 3.735 & .000 \\
\hline Frequency of PD opportunities & .129 & 6.734 & .000 & .063 & 1.734 & .000 \\
\hline Capacity-building PD & .166 & 8.732 & .000 & .037 & 2.732 & .000 \\
\hline \multicolumn{7}{|l|}{ Teaming and collaboration } \\
\hline Professional discipline & .021 & 1.777 & .000 & .021 & 1.777 & .000 \\
\hline Years of practitioner experience & .025 & 2.776 & .000 & .004 & 1.766 & .090 \\
\hline Child age & .030 & 5.773 & .000 & .006 & 3.773 & .219 \\
\hline Frequency of PD opportunities & .096 & 6.772 & .000 & .065 & 1.772 & .000 \\
\hline Capacity-building PD & .321 & 8.770 & .000 & .225 & 2.770 & .000 \\
\hline \multicolumn{7}{|l|}{ Transition practices } \\
\hline Professional discipline & .008 & 1.746 & .016 & .008 & 1.746 & .016 \\
\hline Years of practitioner experience & .028 & 2.745 & .000 & .020 & 1.745 & .000 \\
\hline Child age & .038 & 5.742 & .000 & .010 & 3.742 & .050 \\
\hline Frequency of PD opportunities & .101 & 6.741 & .000 & .064 & 1.741 & .000 \\
\hline Capacity-building PD & .262 & 8.739 & .000 & .161 & 2.739 & .000 \\
\hline
\end{tabular}

\subsection{Incremental Results}

The independent contributions of the predictor variables to variations in the practitioners' reported use of the recommended practices are evidenced in the results from the incremental variance analyses. Table 2 includes the unique contributions of each of the predictor variables after the variance accounted for by the variables already 
entered into the analyses were removed.

Professional discipline (education vs. other) was significantly related to practitioners' reported use of 7 of the 10 recommended practices. Educators reported more frequent use of traditional assessment, environment, teaching methods, and instructional adaptation practices compared to respondents with degrees other than education. In contrast, respondents with degrees other than education reported more frequent use of authentic assessment, family capacity-building, teaming and collaboration, and transition practices.

Years of experience working with birth to 5-year-old children accounted for significant amounts of variance in practitioners reported use of all 10 recommended practices. In all 10 sets of analyses, practitioners with more years of experience reported more frequent use of the recommended practices beyond that accounted for by professional discipline. The relationships between years of experience and practitioner use of early childhood intervention practices are similar to those found in other studies (e.g., Ghaith \& Yaghi, 1997; Weintraub Moore \& Wilcox, 2006).

The ages of the children served by the practitioners accounted for significant amounts of variance in the reported use of 6 of the 10 recommended practices beyond that accounted for by professional discipline and years of experience. Practitioners working with birth to 3-year-old children reported more frequent use of authentic assessment, family relationship-building, family capacity-building, and transition practices compared to practitioners working with 3- to 5-year-old children. In contrast, practitioners working with 3- to 5-year-old children reported more frequent use of environmental arrangements and instructional adaptation practices compared to practitioners working with birth to 3-year-old children. The results are consistent with differences in birth to three early intervention programs and 3- to 5-year-old preschool programs in the United States (compare e.g., Klein \& Chen, 2008; Weinstein, 1987). There were no differences between the reported use of the recommended practices for practitioners working with birth to 3-year-old children compared to birth to 5 -year-old children, nor were there any differences between reported use of the practices between practitioners working with birth to 3-year-old children compared to practitioners working with both preschool-aged and older children.

In all 10 sets of analyses, the PD measures accounted for significant amounts of variance in practitioners' reported use of the recommended practices beyond that associated with the three background measures (Research Question 2). More frequent engagement in PD was associated with more frequently reported use of all 10 recommended practices. The average percent of variance accounted for in the reported use of the practices by frequency of $\mathrm{PD}$ beyond that associated with the three background variables was $4 \%(\mathrm{SD}=2)$.

The evidence-based capacity-building PD measures also accounted for significant amounts of variance in the practitioners reported use of all 10 recommended practices beyond that associated with the other four sets of predictors. The variance accounted for ranged between 4\% (Authentic Assessment Practices and Instructional Adaptation Practices) and 23\% (Teaming and Collaboration Practices). The average amount of variance accounted for by these two PD predictors was $9 \%(\mathrm{SD}=6)$. The results are consistent with findings from other studies (e.g., Dunst et al., 2015) where variations in PDS use of evidence-based capacity-building PD practices was associated with differences in practitioners reported use of early childhood intervention practices (Research Question 3).

\subsection{Professional Development Effects}

The extent to which all three PD measures were related to the practitioners' reported use of the recommended practices beyond that associated with the three practitioner background variables was determined by the same hierarchical regression analyses with all three PD measures entered as a set after the effects of three background measures were removed from the analyses. The three PD measures were significantly related to the reported use of all 10 recommended practices with the variance accounted for ranging between 7\% (Assistive Technology), $F(3,814)=20.84, p=.0000$, and 29\% (Teaming and Collaboration), $F(3,770)=105.00, p=.0000$. The average amount of variance accounted for in the practitioners' reported use of the recommended practices was $13 \%$ (SD $=7$ ). The results indicate that more frequent provision of evidence-based capacity-building PD is more likely to be associated with more frequent use of different kinds of early childhood intervention practices. The results are consistent with findings in studies of the relationships between evidence-based and capacity-building PD and practitioner use of child, family, and practitioner early childhood intervention practices (Dunst \& Raab, 2010; Dunst, Trivette, \& Deal, 2011).

\section{Discussion and Conclusion}

The results, taken together, indicated that practitioner use of recommended practices was multiply determined. 
This suggests that factors influencing early childhood practitioner use of different kinds of intervention practices can be best understood in terms of a framework where different factors can be expected to influence practitioner behavior (e.g., Moen, Elder, \& Lüscher, 1995; Wachs, 2000).

Findings indicated that different kinds of practitioner background characteristics were related to the reported use of different kinds of early childhood intervention practices in a manner consistent with previous research (e.g., Ghaith \& Yaghi, 1997; Schachter et al., 2016). Results also indicated that the different PD practices measures accounted for significant amounts of variance in the practitioners' reported use of 10 different early childhood intervention practices beyond that accounted for by the three practitioner background variables. The results point to the relative importance of evidence-based capacity-building PD practices as a factor influencing the reported use of different kinds of recommended early childhood intervention practices. This indicates a need to be cognizant of the fact that how PD is provided is as important, if not more important, than just how often PD is provided if the benefits include practitioner beliefs about the ability to adopt and use the practices in a competent manner.

The pattern of results are consistent with those found in research syntheses of adult learning (Callahan, Kiker, \& Cross, 2003; Dunst \& Hamby, 2015a; Dunst et al., 2010) and in-service PD (Dunst et al., 2015; Egert et al., 2018; Showers, Joyce, \& Bennett, 1987) studies where combinations of PD practices best explained optimal learner outcomes. That is, the PD measures associated with practitioner reported or actual use of the practices that were the focus of investigation in previous research were the same measures found to be related to practitioner reported use of the DEC recommended practices in our study. Results indicated that practitioners who reported PDS use of the four types of PD examined in the study and who judged those practices as having capacity-building effects were the same practitioners who reported more frequent use of the 10 early childhood intervention practices that were the focus of investigation.

In terms of the three research questions guiding the conduct of the study, the results showed that: (1) Practitioner judgments of $\mathrm{PD}$ were related to the reported use of the 10 practices constituting the focus of investigation (Research Question 1), (2) the PD measures accounted for significant amounts of variance in the reported use of the DEC recommended practices beyond that accounted for by the three background measures (Research Question 2), and (3) the PD measures were differently related to the reported use of the DEC recommended practices (Research Question 3). The results pertaining to Questions 1 and 2 mirror the results found in other studies of the types of PD that were the focus of investigation.

The fact that the PD measures were differentially related to the practitioners' reported use of the 10 recommended practices was as expected and as hypothesized. Findings from a meta-analysis of the types of PD used to promote practitioners' and family members' use of assistive technology with young children with disabilities (Dunst \& Hamby, 2015b) and a metasynthesis of the relationships between teacher preparation practices and teachers' use of different kinds instructional practices (Dunst, Hamby, Howse, Wilkie, \& Annas, 2019,2020 ) were similar to those found in our investigation. In both research syntheses, the types of PD that were the focus of analysis in our study were found to be differentially related to different types of teacher and practitioner intervention practices. What remains to be investigated is what combinations of what types of PD are related to which types of practitioner use of different types of early childhood intervention practices.

\subsection{Implications for Policy and Practice}

Policymakers often have to decide about the allocation of resources to improve program, organizational, and practitioner practices. One such area is the type of in-service PD afforded teachers and other practitioners. Policymakers and other leaders play an important role in decisions about what types of professional development that ought to be used to achieve program and organizational goals.

Results from the study described in this paper and elsewhere (e.g., Dunst et al., 2015; Dunst et al., 2010) can inform policy decisions by insisting that professional development offered to or procured for teachers and practitioners include practices identified as most important for promoting adoption and use of desired intervention practices (see Dunst, 2013). More specifically, the results can be used to evaluate whether a PDS or other trainer being asked to provide PD to early childhood intervention practitioners is planning to do so in a way that includes evidence-based capacity-building core elements. The results can also be used to evaluate whether practitioner requested PD from a PDS or other trainer is likely to have positive benefits in terms of practitioner adoption and use of the practices that are the focus of PD.

These contentions are not limited to early childhood intervention. Noted experts have "called for" the use of the type of professional development examined in our study in early intervention, preschool, elementary, and secondary education (e.g., Desimone, 2009; Guskey, 2002) as have researchers and practitioners also concerned 
with the use of evidence-based professional development practices to improve practitioner use of recommended and evidence-based intervention practices (e.g., Getenet, Trimble, \& Nailon, 2013; Ingvarson, Beavis, \& Kleinhenz, 2007).

\subsection{Limitations}

Several limitations need to be mentioned to place the study in procedural and methodological context. First, the study was conducted in only one state and the results might not generalize to other states, and especially ones with different types of service delivery systems. Second, several professional development survey questions were open to different interpretations, and may therefore not constitute the best measures of the constructs used as predictor variables. Third, the study was correlational in nature in terms of the relationships between the predictor measures and recommended practices measures, and therefore causal explanations may not be warranted. Notwithstanding these limitations, the results add to the literature in terms of our understanding of what types of professional development practices are related to which types of early childhood intervention practices.

\section{Acknowledgments}

The preparation of this paper was supported, in part, by funding from the U.S. Department of Education, Office of Special Education Programs (No. 325B120004) for the Early Childhood Personnel Center, University of Connecticut Health Center. The contents and opinions expressed, however, are those of the authors and do not necessarily reflect the policy or official position of the U.S. Department of Education, Office of Special Education Programs, University of Connecticut Health Center, or the Early Childhood Personnel Center, and no endorsement should be inferred or implied.

\section{References}

Alkharusi, H. (2012). Categorical variables in regression analysis: A comparison of dummy and effect coding. International Journal of Education, 4(2), 202-210. https://doi.org/10.5296/ije.v4i2.1962

Bandura, A. (1997). Self-efficacy: The exercise of control. New York: Freeman.

Bozack, A. R. (2008). Growing new teachers: The relationship among professional development, efficacy beliefs, and classroom practices. Dissertation Abstracts International Section A: Humanities and Social Sciences, 69(2-A).

Bruder, M. B., \& Dunst, C. J. (2008). Factors related to the scope of early intervention service coordinator $\begin{array}{lllll}\text { practices. Infants } & \text { Ynd }\end{array}$ https://doi.org/10.1097/01.IYC.0000324547.54693.18

Bruder, M. B., Dunst, C. J., Wilson, C., \& Stayton, V. (2013). Predictors of confidence and competence among early childhood interventionists. Journal of Early Childhood Teacher Education, 34(3), 249-267. https://doi.org/10.1080/10901027.2013.816806

Callahan, J. S., Kiker, D. S., \& Cross, T. (2003). Does method matter? A meta-analysis of the effects of training method on older learner training performance. Journal of Management, 29, 663-680. https://doi.org/10.1016/S0149-2063_03_00029-1

Cohen, J., Cohen, P., West, S. G., \& Aiken, L. S. (2003). Applied multiple regression/correlation analysis for the behavioral sciences (3rd ed.). Mahwah, NJ: Erlbaum.

Darling-Hammond, L., \& McLaughlin, M. W. (1995). Policies that support professional development in an era of reform. Phi Delta Kappan, 76(8), 597-604.

Davis, M. J. (2010). Contrast coding in multiple regression analysis: Strengths, weaknesses, and utility of popular coding structures. Journal of Data Science, 8, 61-73.

Desimone, L. M. (2009). Improving impact studies of teachers' professional development: Toward better conceptualizations and measures. Educational Researcher, 38(3), 181-199. https://doi.org/10.3102/0013189X08331140

Di Franco, M., \& Marradi, A. (2013). Factor analysis and principal component analysis. Milan, Italy: FrancoAngeli.

Division for Early Childhood. (2014). DEC recommended practices in early intervention/early childhood special education. Retrieved from http://www.dec-sped.org/recommendedpractices

Downer, J. T., Locasale-Crouch, J., Hamre, B., \& Pianta, R. (2009). Teacher characteristics associated with 
responsiveness and exposure to consultation and online professional development resources. Early Education and Development, 20, 431-455. https://doi.org/10.1080/10409280802688626

Dunst, C. J. (2013). Guide for evaluating professional development: Opportunities in early childhood education. The Early Childhood Educator, 28(3), 7-10. Retrieved from http://www.puckett.org/PD-Guide.pdf

Dunst, C. J., \& Bruder, M. B. (2014). Preservice professional preparation and teachers' self-efficacy appraisals of natural environment and inclusion practices. Teacher Education and Special Education, 37(2), 121-132. https://doi.org/10.1177/0888406413505873

Dunst, C. J., \& Hamby, D. W. (2015a). A case study approach to secondary reanalysis of a quantitative research synthesis of adult learning practices studies. International Journal of Learning, Teaching and Educational Research, 13(3), 181-191. Retrieved from https://www.ijlter.org/index.php/ijlter/article/view/456

Dunst, C. J., \& Hamby, D. W. (2015b). Research synthesis of studies to promote parent and practitioner use of assistive technology and adaptations with young children with disabilities. In D. L. Edyburn (Ed.), Advances in special education technology (Vol. 1): Efficacy of assistive technology interventions (pp. 51-78). United Kingdom: Emerald Publishing. https://doi.org/10.1108/S2056-769320150000001003

Dunst, C. J., \& Raab, M. (2010). Practitioners' self-evaluations of contrasting types of professional development. Journal of Early Intervention, 32, 239-254. https://doi.org/10.1177/1053815110384702

Dunst, C. J., \& Trivette, C. M. (2012). Moderators of the effectiveness of adult learning method practices. Journal of Social Sciences, 8, 143-148. https://doi.org/10.3844/jssp.2012.143.148

Dunst, C. J., Bruder, M. B., \& Espe-Sherwindt, M. (2014). Family capacity-building in early childhood intervention: Do context and setting matter? School Community Journal, 24(1), 37-48. Retrtieved from http://www.adi.org/journal/2014ss/DunstBruderEspe-SherwindtSpring2014.pdf

Dunst, C. J., Bruder, M. B., \& Hamby, D. W. (2015). Metasynthesis of in-service professional development research: Features associated with positive educator and student outcomes Educational Research and Reviews, 10(12), 1731-1744. https://doi.org/10.5897/ERR2015.2306

Dunst, C. J., Espe-Sherwindt, M., \& Hamby, D. W. (2019). Does capacity-building professional development engender practitioners' use of capacity-building family-centered practices? European Journal of Educational Research, 8(2), 515-526. https://doi.org/10.12973/eu-jer.8.2.513

Dunst, C. J., Hamby, D. W., Howse, R. B., Wilkie, H., \& Annas, K. (2019). Metasynthesis of preservice professional preparation and teacher education research studies. Education Sciences, 9(50), https://doi.org/10.3390/educsci9010050

Dunst, C. J., Hamby, D. W., Howse, R. B., Wilkie, H., \& Annas, K. (2020). Research synthesis of meta-analyses of preservice teacher preparation practices in higher education. Higher Education Studies, 10(1), 29-47. https://doi.org/10.5539/hes.v10n1p29

Dunst, C. J., Trivette, C. M., \& Deal, A. G. (2011). Effects of in-service training on early intervention practitioners' use of family systems intervention practices in the USA. Professional Development in Education, 37, 181-196. https://doi.org/10.1080/19415257.2010.527779

Dunst, C. J., Trivette, C. M., \& Hamby, D. W. (2010). Meta-analysis of the effectiveness of four adult learning methods and strategies. International Journal of Continuing Education and Lifelong Learning, 3(1), 91-112. Retrieved from http://www.puckett.org/Meta-analysis-effectiveness-four-adult-learning-methods-strategies. pdf

Egert, F., Fukkink, R. G., \& Eckhardt, A. G. (2018). Impact of in-service professional development programs for early childhood teachers on quality ratings and child outcomes: A meta-analysis. Review of Educational Research, 88(3), 401-433. https://doi.org/10.3102/0034654317751918

Erickson, A. S. G., Noonan, P. M., Brussow, J., \& Carter, K. S. (2017). Measuring the quality of professional development training. Professional Development in Education, 43(4), 685-688. https://doi.org/10.1080/19415257.2016.1179665

Getenet, S., Trimble, A., \& Nailon, D. (2013). Perspectives on professional development in Australian education: Some realities of standards-based professional development. International Journal of Innovative Interdisciplinary Research, 2(2), 34-48.

Ghaith, G., \& Yaghi, H. (1997). Relationships among experience, teacher efficacy, and attitudes toward the implementation of instructional innovation. Teaching and Teacher Education, 13, 451-458. 
https://doi.org/10.1016/S0742-051X(96)00045-5

Guskey, T. R. (2002). Professional development and teacher change. Teacher and Teaching: Theory and Practice, 8(3/4), 381-391. https://doi.org/10.1080/135406002100000512

Guskey, T. R., \& Yoon, K. S. (2009). What works in professional development? Phi Delta Kappan, 90, 495-500. https://doi.org/10.1177/003172170909000709

Hider, E. D. (2000). A qualitative study of the child, family and professional factors that influence the use of assistive technology in early intervention. In J. Lemke (Ed.), Capitalizing on leadership in rural special education: Making a difference for children and families: Conference proceedings of the American Council on Rural Special Education. Alexandria, VA: American Council on Rural Special Education. (ERIC Document Reproduction Service No. ED439872).

Ingvarson, L., Beavis, A., \& Kleinhenz, E. (2007). Factors affecting the impact of teacher education programmes on teacher preparedness: Implications for accreditation policy. European Journal of Teacher Education, 30, 351-381. https://doi.org/10.1080/02619760701664151

Klein, M. D., \& Chen, D. (2008). Home visiting practices in early intervention with infants with disabilities: An exploratory study. Early Childhood Services: An Interdisciplinary Journal of Effectiveness, 2, 207-224.

Knoche, L. L., Kuhn, M., \& Eum, J. M. A. (2013). "More time. More showing. More helping. That's how it sticks": The perspectives of early childhood coachees. Infants \& Young Children, 26(4), 349-365. https://doi.org/10.1097/IYC.0b013e3182a21935

Martinez, C. G. L. (2017). Interventionists' use of parent engagement strategies in early intervention services for young children at-risk for autism (Masters Thesis). San Diego State University, San Diego, CA. Retrieved from https://search.proquest.com/openview/152a4575098186ba4a89aa016690b0cb/1?pq-origsite=gscholar $\& \mathrm{cbl}=18750 \&$ diss $=\mathrm{y}$

McKenzie, E. N. (2013). National Board Certification and Developmentally Appropriate Practices: Perceptions of impact. Journal of Research in Childhood Education, 27(2), 153-165. https://doi.org/10.1080/02568543.2013.766661

McMullen, M. B. (1997). The effects of early childhood academic and professional experience on self perceptions and beliefs about developmentally appropriate practices. Journal of Early Childhood Teacher Education, 18, 55-68. https://doi.org/10.1080/1090102970180307

McWilliam, R. A., \& Bailey Jr., D. B. (1994). Predictors of service-delivery models in center-based early intervention. Exceptional Children, 61, 56-71. https://doi.org/10.1177/001440299406100106

Moen, P., Elder Jr., G. H., \& Lüscher, K. (Eds.). (1995). Examining lives in context: Perspectives on the ecology of human development. Washington, DC: American Psychological Association. https://doi.org/10.1037/10176-000

Park, J., \& Turnbull, A. P. (2003). Service integration in early intervention: Determining interpersonal and structural factors for its success. Infants and Young Children, 16(1), 48-58. https://doi.org/10.1097/00001163-200301000-00006

Rapport, M. J., McWilliam, R. A., \& Smith, B. J. (2004). Practices across disciplines in early intervention: The $\begin{array}{lllll}\text { research base. Infants and Young Children, } & \text { 17(1), }\end{array}$ https://doi.org/10.1097/00001163-200401000-00006

Rosenberg, L., Bart, O., Ratzon, N. Z., \& Jarus, T. (2013). Personal and environmental factors predict participation of children with and without mild developmental disabilities. Journal of Child and Family Studies, 22(5), 658-671. https://doi.org/10.1007/s10826-012-9619-8

Ruble, L., \& McGrew, J. H. (2013). Teacher and child predictors of achieving IEP goals of children with autism. Journal of Autism and Developmental Disorders, 43(12). https://doi.org/10.1007/s10803-013-1884-x

Schachter, R. E., Spear, C. F., Piasta, S. B., Justice, L. M., \& Logan, J. A. R. (2016). Early childhood educators' knowledge, beliefs, education, experiences, and children's language- and literacy-learning opportunities: What is the connection? Early Childhood Research Quarterly, 36, 281-294. https://doi.org/10.1016/j.ecresq.2016.01.008

Sheppard, B., Brown, J., \& Dibbon, D. (2009). Professional development and capacity building. In B. Sheppard, J. Brown, \& D. Dibbon (Eds.), School district leadership matters (pp. 85-100). Basel, Switzerland: Springer International. https://doi.org/10.1007/978-1-4020-9747-8_6 
Showers, B., Joyce, B., \& Bennett, B. (1987). Synthesis of research on staff development: A framework for future study and a state-of-the-art analysis. Educational Leadership, 45(3), 77-87.

Turner, K. M. T., Nicholson, J. M., \& Sanders, M. R. (2011). The role of practitioner self-efficacy, training, program and workplace factors on the implementation of an evidence-based parenting intervention in primary care. Journal of Primary Prevention, 32(2), 95-112. https://doi.org/10.1007/s10935-011-0240-1

Van keer, I., \& Maes, B. (2016). Contextual factors influencing the developmental characteristics of young children with severe to profound intellectual disability: A critical review. Journal of Intellectual \& Developmental Disability, 1-19. https://doi.org/10.3109/13668250.2016.1252458

Wachs, T. D. (2000). Necessary but not sufficient: The respective roles of single and multiple influences on individual development. Washington, DC: American Psychological Association. https://doi.org/10.1037/10344-000

Weinstein, C. S. (1987). Designing preschool classrooms to support development: Research and reflection. In C. S. Weinstein, \& T. G. David (Eds.), Spaces for children: The built environment and child development (pp. 159-185). New York, NY: Plenum Press. https://doi.org/10.1007/978-1-4684-5227-3_8

Weintraub Moore, H., \& Wilcox, M. (2006). AT and young children: Confidence, experience, and education of early intervention providers. Topics in Early Childhood Special Education, 26, 15-24. https://doi.org/10.1177/02711214060260010201

Yoo, J. H. (2016). The effects of professional development on teacher efficacy and teachers' self-analysis of their efficacy change. Journal of Teacher Education for Sustainability, 18(1), 84-94. https://doi.org/10.1515/jtes-2016-0007

\section{Copyrights}

Copyright for this article is retained by the author(s), with first publication rights granted to the journal.

This is an open-access article distributed under the terms and conditions of the Creative Commons Attribution license (http://creativecommons.org/licenses/by/4.0/). 